\title{
Reading science
}

\author{
Scientists are often accused of poorly communicating their findings, but improving scientific literacy is \\ everyone's responsibility.
}

Scientific reports are not very readable. That's the conclusion of Ralf Barkemeyer and colleagues, who conducted a linguistic analysis of the Summary for Policymakers (SPM) documents that accompanied the Intergovernmental Panel on Climate Change's (IPCC) Fifth Assessment Report (AR5) (page 311). In contrast, they found that most media reports on AR5 scored very well, according to their readability metric.

Although this finding is perhaps not surprising, it is potentially problematic. The SPM is supposed to translate the IPCC's headline findings into a usable language for those charged with cutting the world's greenhouse gas emissions. If they are unusually difficult to read, then they are arguably not performing their principal function - indeed, Barkemeyer et al. found that even seminal physics papers by Albert Einstein and Stephen Hawking had considerably higher readability scores.
The esoteric style of the SPM means that policymakers and the public are likely to go elsewhere for scientific information. That could be dangerous, as information is liable to get lost or be miscommunicated in translation. So, the argument goes, scientists should improve their communication skills, and ensure that documents such as the SPM are written in a manner that most people can understand.

But such calls for the democratization of science - whereby even the most complex findings are accessible to everyone - cuts both ways. The research by Barkemeyer et al. shows that the established process of scientific reporting is actually functioning reasonably well. Scientists report scientific research, and journalists translate this into digestible findings for the public.

If the concern is that those findings are miscommunicated, there is a good argument for raising levels of scientific literacy in general, as well as making the reports easier to read.

Currently, only 2 members of US Congress have natural science PhDs. In the UK, only 6 of 650 Members of Parliament have science degrees. If decision makers had higher levels of scientific literacy, the quality of the translations becomes less important. Likewise, if the public were more scientifically literate, then the readability of the SPM becomes less significant.

It may be wise to provide communications training for scientists, which is an idea that the IPCC is already exploring. But perhaps journalists and politicians should also be sent to science classes - teaching the skills to read science at its source should be a greater priority across the board. Everyone must take their share of responsibility in the march towards more accessible science.

\section{Topping the tables}

\section{Failure of climate change mitigation and adaptation ranks as the most impactful risk to society, according to the 2016 Global Risks Report from the World Economic Forum.}

The Global Risks Report released by the World Economic Forum (WEF) last year presented a mixed outlook for the run up to the UN Paris climate negotiations (Nature Clim. Change 5, 175; 2015). On one hand, environmental risks had been marching steadily up the perceived risk rankings, whereas on the other there were signs of dwindling levels of international trust and cooperation.

However, the climate negotiations played out better than many might have expected. It is interesting, then, that in the latest WEF Global Risks

Report (http://www.

weforum.org/reports/ the-global-risksreport-2016) 'failure of climate change mitigation and adaptation' is the top ranked risk in terms

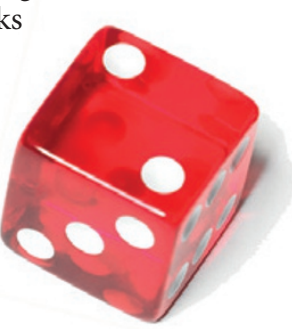

of its perceived impact on society. It also ranks third in terms of likelihood, after large-scale involuntary migration (which is already happening) and extreme weather events, which have been well represented during 2015.

This essentially means that respondents think that a failure to address this issue is likely to lead to levels of climate change that pose serious risks to society, potentially beyond our capacity to adapt within the

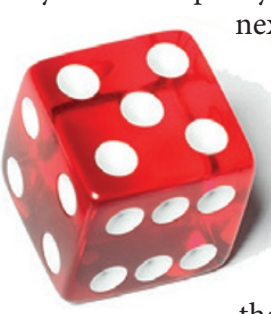
next ten years.

The risks report is based on a survey of 750 individuals and was undertaken during September and October 2015, so the outcomes of the Paris negotiations were not yet known. Nevertheless, knowledge of the Paris Agreement would not be expected to alter perceptions of the potential impacts of climate change, should they occur, even if it might affect perceptions of their likelihood.

The WEF risks report is notable for several reasons. First, different types of risk are explicitly ranked alongside one another. That the failure to address climate change tops the tables above fiscal crises and even weapons of mass destruction is significant.

Moreover, those surveyed by the WEF are skewed towards individuals whose expertise lays in economics (34.5\%) and are working in the private sector $(44.7 \%)$; for comparison, only $10 \%$ have primary expertise in the environment. If broad recognition that there is a problem is a first step towards social and political solutions, then perhaps there is some room for optimism, as well as healthy debate about what those solutions could and should look like. 